Review Article

\title{
An Overview on Spinning Mechanism, Yarn Structure and Advantageous Characteristics of Vortex Spun Yarn and Fabric
}

\author{
Hosne Ara Begum ${ }^{1}$, Md. Khalilur Rahman Khan ${ }^{2, *}$, Md. Merajur Rahman ${ }^{2}$ \\ ${ }^{1}$ Department of Yarn Engineering, Bangladesh University of Textiles, Dhaka, Bangladesh \\ ${ }^{2}$ Department of Textile Engineering, Bangladesh University of Business and Technology, Dhaka, Bangladesh \\ Email address: \\ khalilbutex $a$ gmail.com (Md. K. R. Khan), merajtex39 a gmail.com (Md. M. Rahman) \\ ${ }^{*}$ Corresponding author
}

\section{To cite this article:}

Hosne Ara Begum, Md. Khalilur Rahman Khan, Md. Merajur Rahman. An Overview on Spinning Mechanism, Yarn Structure and Advantageous Characteristics of Vortex Spun Yarn and Fabric. Advances in Applied Sciences. Vol. 3, No. 5, 2018, pp. 58-64. doi: $10.11648 /$ j.aas.20180305.11

Received: August 14, 2018; Accepted: September 30, 2018; Published: November 26, 2018

\begin{abstract}
Spinning systems based on mechanical twisting device have their limitations in terms of technical feasibility and economic viability. Making effort on yarn formation with the swirling air concept arouse of interest of the researchers for a long time. Air jet spinning had offered this opportunity for yarn manufacturers to produce yarn at relatively high production rate. Vortex spinning technology is a modified form of air-jet spinning which has attracted a lot of attention because of its advantages over ring spinning, open end and air-jet spinning in terms of production rate and yarn quality parameters. In this study, with stating some historical background, the mechanism of vortex spinning, structure and characteristics of vortex spun yarn have been overviewed. The body of vortex yarn is mainly constituted with twistless and parallel core fiber held together by helical surface wrapper fibers. All designated fiber types are found in vortex yarn such as wild fibers, belly band fibers, parallel and helical fibers. In case of quality consideration, air-vortex yarn has higher values of tenacity compared to the rotor yarn \& air-jet yarn. This yarn has also improved characteristics compared to the ring and rotor yarns in terms of hairiness, evenness and bending rigidity. On the other hand, the advantageous properties of fabric produced from vortex yarn such as pilling resistance, delicate printing capability, comfort characteristics etc. have been discussed. Finally, advantages obtained in some post spinning processes such as sizing, better loom shedding, drying of fabric after dyeing etc have also been mentioned in this paper.
\end{abstract}

Keywords: Vortex Spinning, Vortex Yarn Structure, Yarn Characteristics, Fabric Properties

\section{Introduction}

The spinning industry is gradually developing to increase production, improve quality and reduce costs. Traditional spinning systems are reaching profitability limits due to high production costs and low productivity [1]. For several decades, the evolution of spinning technology focused on improving the productivity with good quality [2]. The majority of recent developments in yarn production have been refinements of existing spinning techniques. By removing the mechanical twisting methods, Pneumatic spinning is seen as a developing system; its productivity is much higher than that achieved by conventional systems. It is worth mentioning that certain others advantages of modern spinning systems are lower power consumption per kg of yarn produced, larger delivery package (up to $6 \mathrm{~kg}$ ), elimination of some processes, reduced labour requirements, etc.

On the other hand, structure plays a very important role in textile goods such as yarn. Each spinning system produces yarns with different structures [3]. In yarn production, the mechanism of twist insertion is a major factor that affects the structure and ultimately the properties and characteristics of 
the produced yarn [4]. In yarn spinning process, air, in particular high speed air has been used for the twisting of staple fibres.

Air-jet spinning is the most promising spinning method at the beginning of the twenty-first century. The spinning system is one of the unconventional systems for yarn manufacturing, classified into the group of jet spinning [5]. The latest development in air-jet spinning technology is the murata vortex spinner (MVS), which was first introduced at the Osaka International Textile Machinery Show (OTEMAS) '97 by Murata Machinery Ltd [6].

The VORTEX III 870 boasts the world's fastest spinning of staple yarns at $500 \mathrm{~m} / \mathrm{min}$. This provides 20 times the production of ring spinning. The Vortex provides 3 times the productivity even against OE spinning [7].

The superior pilling resistance, external appearance, printability and other characteristics of VORTEX yarns and fabrics have been recognized all over the world and have greatly expanded the product development possibilities in the fashion world.

Globalization has significant effects on the textile industry, including yarn production. This means that a yarn producer must therefore be technologically aware, efficient, flexible and cost conscious. Detailed understanding of technology and engineering provides the fuel for innovation and success in the textile industry [8]. Comprehending the modern technology will certainly affect the future setup of spinning industry in Bangladesh. From this perspective, it is attempted to make an overview of historical background, spinning mechanism, technical parameters, yarn structure and properties of vortex spun yarn. Properties of fabrics made of vortex yarn and advantages in post spinning process have also been discussed.

\section{Historical Background}

Vortex spinning system is the latest development in air-jet spinning technology. The use of high-speed airflow in spinning system for inserting twist was desired by many researchers. But Murata Machinery Ltd. from Japan has developed the most commercially successful air-jet spinning machines to date and continues to dominate globally the air-jet spinning technology. The company introduced its first air-jet spinning machine, Murata Jet Spinner, MJS 801, at the American Textile Machinery Exhibition in 1982 (ATME '82). The system is stated to be suitable for processing man-made fibres and their blends with cotton; however, it was not capable of spinning $100 \%$ cotton or rich blends of cotton yarn. Subsequently, Murata modified the drafting systems and developed new nozzle designs and also claimed to be capable of spinning $100 \%$ cotton.

At the International Textile Machinery Exhibition in 1983 (ITMA '83), Toyoda and Howa from Japan exhibited their air- jet spinning systems, however; these two systems had little commercial success.

Another Japan-based manufacturer, Toray, exhibited its first air-jet spinning machine, the AJS 101, at the American Textile Machinery Exhibition in 1985 (ATME '85). The system was suitable for short-staple man-made fibers and their blends with cotton. The machine was later improved so as to contain more automation and be able to achieve higher speeds, but this also had no commercial impact. Later, Murata introduced Roller Jet Spinner RJS 804 at International Textile Machinery Exhibition in 1995 (ITMA '95) with the production speed of up to $400 \mathrm{~m} / \mathrm{min}$.

The latest concept in air-jet spinning developed by Murata Machinery Ltd. is known as the vortex spinning system, which uses a modified single air nozzle. This system is claimed to be capable of producing $100 \%$ carded cotton yarns, which have a ring spun like appearance.

The first vortex spinning machine the Murata MVS 810 was exhibited at Osaka International Textile Machinery Show in 1997 (OTEMAS'97). The machine had a delivery speed of up to $400 \mathrm{~m} / \mathrm{min}$. The modified version of this machine, MVS $81 \mathrm{~T}$, was developed to produce twin vortex-spun yarns. The yarns spun on two spinning units pass through the same yarn cleaning and waxing unit and are wound on the same package. These are twisted on a two-for-one twister to obtain a plied vortex yarn. Subsequently, Murata introduced the MVS 851 spinning machine. Different from the previous machine, MVS 851 is not capable of spinning core yarns. Murata exhibited a new version of vortex spinning machine, the MVS 861, in 2003. This version allowed the spinning of core yarns and achieved higher delivery speeds of up to $450 \mathrm{~m} / \mathrm{min}$. Recently, Murata introduced its third generation vortex spinning machine, Vortex III 870, at ITMA 2011. This machine is available for up to 96 units with a maximum production speed of $500 \mathrm{~m} / \mathrm{min}$.

Rieter from Switzerland introduced their J10 air-jet spinning machine at the 2009 International Textile Machinery Exhibition in Istanbul. The machine was claimed to allow yarn delivery speed of up to $450 \mathrm{~m} / \mathrm{min}$., and the yarn spun on this machine is marketed under the "ComforJetR" trademark. At ITMA 2011, Rieter exhibited J20 air-jet spinning machine. It is a double-sided machine with 120 spinning units; therefore, it offers flexibility and high productivity with minimum space requirements [9].

\section{Basic Mechanism of Vortex Spinning}

In the vortex spinning system (Figure 1) a finisher sliver is supplied directly to a four roller/apron drafting unit. As the fibers come out of the front rollers, they are sucked into the spiral-shaped opening of the air jet nozzle. 


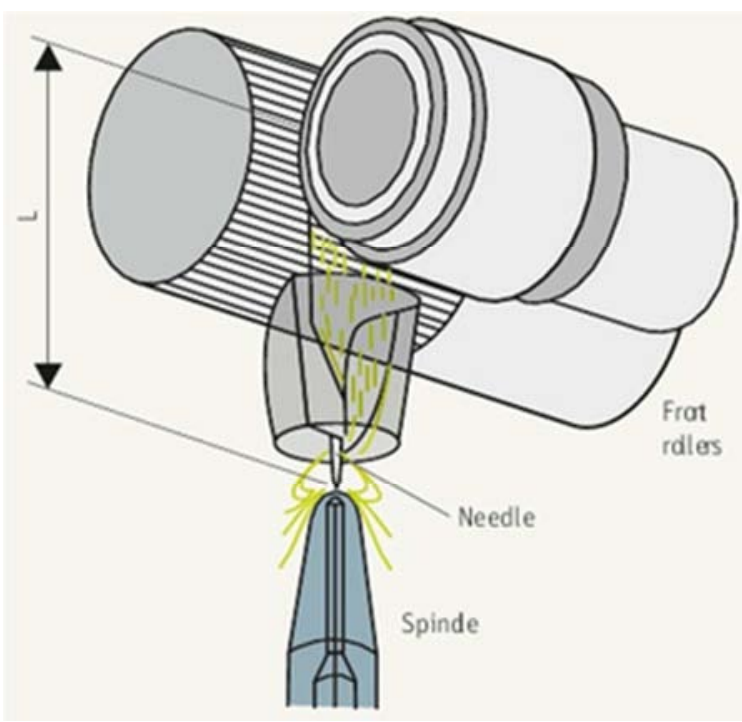

Figure 1. Vortex spinning [10].

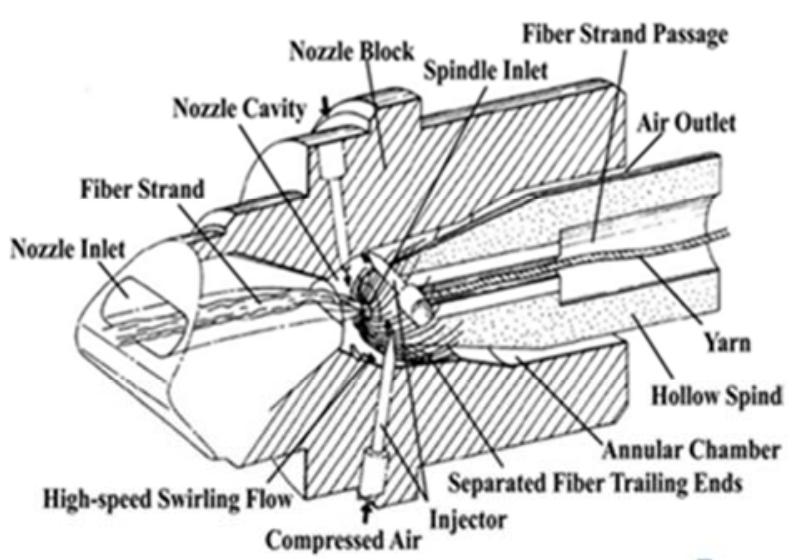

Figure 2. Nozzle block of vortex spinning [11].

This air-jet device includes a nozzle block (shown in Figure $2 \& 3$ ) with injectors for the generation of swirl flow, a needle holder, a hollow spindle and a guide member. A needle holder (shown in Figure 3) within the nozzle controls the movement of the fibers towards a hollow spindle. A pin-like guide member associated with the needle holder protrudes toward the inlet of the spindle. The nozzle block is provided with several injectors that are tangential to the cylindrical nozzle cavity and are slightly inclined in the direction of the movement of the fiber strand which enters the nozzle block from the inlet. The hollow spindle provided with a conical portion in its inlet end locates slightly downstream of the injectors and defines a coaxial fiber strand passage whose inlet portion has a relatively small diameter. The conical portion of the spindle is surrounded by the nozzle block and an annular chamber which connects the nozzle cavity and the outside is formed. Compressed air is jetted into the nozzle cavity through the injectors to produce the high-speed swirling flow in the vicinity of the inlet of the spindle. The swirling air stream whirls downstream in the annular chamber and flows outside through the air outlet.

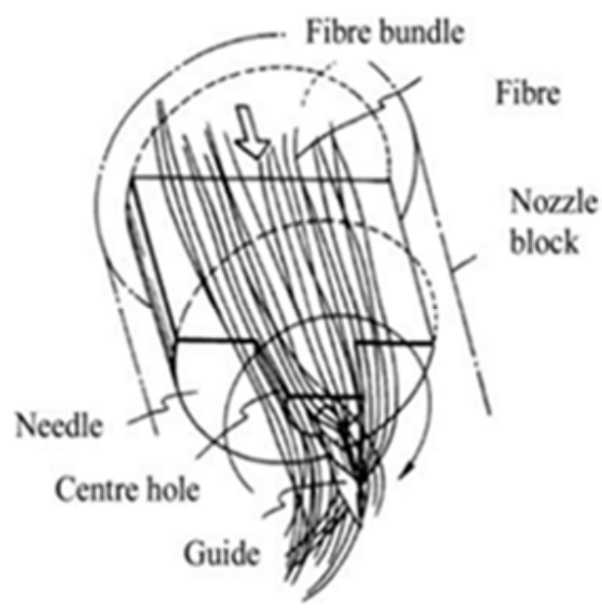

Figure 3. Needle holder with guide member [9].

Twist insertion starts as the fiber bundle receives the force of the compressed air at the inlet of the spindle. The twisting motion tends to propagate from the spindle toward the front rollers. This propagation is prevented by the guide member.

Table 1. Significant specifications/parameters of vortex spinning system [7].

\begin{tabular}{ll}
\hline Specification/ Parameters & Types/Values \\
\hline Raw materials & Cotton $100 \%$, Synthetic/cotton, Synthetic $100 \%$ \\
Yarn count range & $15 \mathrm{Ne}$ to $60 \mathrm{Ne}(\mathrm{Tex} 39-$ Tex 10$)$ \\
Fiber length & $38 \mathrm{~mm}\left(1.5^{\prime}\right)$ max \\
Number of units & $16-96$ \\
Spinning speed & $500 \mathrm{~m} / \mathrm{min}(\mathrm{Max})$. \\
Total draft ratio & 65 to 400 (In case of yarn speed $300 \mathrm{~m} / \mathrm{min})$ \\
Brake draft ratio & 100 to 450 (In case of yarn speed $500 \mathrm{~m} / \mathrm{min})$ \\
Intermediate draft ratio & $1.5-5.0$ \\
Main draft ratio & $1.1 \sim 5.0$ \\
Feed ratio & 15 to $60($ In case of yarn speed $300 \mathrm{~m} / \mathrm{min})$ \\
Take-up ratio & 13.5 to 80 (In case of yarn speed $500 \mathrm{~m} / \mathrm{min})$ \\
Spindle Inner Diameter & 0.9 to 1.1 \\
Nozzle air pressure $\left(\mathrm{kg} / \mathrm{cm}^{2}\right)$ & 0.9 to 1.1 \\
Distance between front roller and the spindle $(\mathrm{mm})$ & $1-1.4 \mathrm{~mm}$ \\
\hline
\end{tabular}

After fibers have left the guide member, the whirling force of the air jet separates fibers from the bundle. Since the leading ends of all fibers are moved forward around the guide member and drawn into the spindle by the preceding portion 
of fiber bundle being formed into a yarn, they present partial twist and are less affected by the air flow inside the spindle. On the other hand, when the trailing ends of the fibers which have left the front rollers move to a position where they receive the powerfully whirling force of the nozzle, they are separated from the fiber bundle, extend outwardly and twine over the spindle. Subsequently, these fibers are spirally wound around the fiber core and formed into a vortex spun yarn like a real twisted spun yarn as they are drawn into the spindle. The finished yarn is wound onto package after its defects have been removed. In table-1, technical specifications/parameters of vortex spinning have been given.

\section{Yarn Structure \& Properties}

\subsection{Yarn Structure}

Yarn structure is one of the primary factors which control the properties of spun yarns [12]. The structure of vortex yarn from air-vortex spinning systems differ from that of air-jet, ring and rotor spun yarns. The vortex spun yarn has a wrapped structure with a core of twistless, parallel fibers held together by helical surface wrapper fibers. In vortex spinning, the leading ends of the fibers in the drafted fiber bundle form the yarn core, while the trailing ends of some fibers are separated from the fiber bundle by the air flow created in the twisting chamber and they form the wrapper fibers [13]. The ratio of wrapper fibers to core fibers is the most decisive structural parameter in the vortex spinning system. The core fibers account for approximately $85-95 \%$ of the air-jet yarn mass [14]. Tyagi et al. investigated the process-structure-property relationship of polyester-cotton vortex yarns. They concluded that vortex yarns made by vortex system consisted of about $50-60 \%$ of core fibers and the rest as wrapper/wild fibers [15].

A vacuum around the base of the spindle blows off almost all short fibres. Thus vortex yarn is claimed to be 'Air-singed' and 'Air-combed' yarn. The special feature of this technique is that, during spinning, long fibres converge to the core and short fibres diverge to the outer layer by air vortex [16].

The ratio of wrapper fibers increases (or the ratio of core fibers decreases) as the yarn becomes finer. While the leading ends of the component fibers of the fiber bundle are drawn into the hollow spindle by the preceding portion of the fiber bundle being formed into the yarn, the trailing ends of some fibers, exposed to the swirling air current are separated from the fiber bundle, form the wrapper fibers. More fibers in the fiber bundle means greater interfiber cohesion, which may restrain the separation of trailing ends of the fibers resulting in fewer wrapper fibers in coarse counts. Besides, the whirling effect of the air stream is expected to be greater when fewer fibers exist in the fiber bundle, which leads to more wrapper fibers. Because of shorter and uneven mean fiber length and therefore poor interfiber cohesion and higher bending rigidity, it is more difficult for cotton fiber to wrap and join the yarn structure properly along the yarn in the yarn formation zone in comparison to polyester. Therefore, cotton fiber is more prone to be disturbed by the air flow created in the yarn formation zone and consequently makes separation of the trailing end of the fibers from the fiber bundle easy [17].

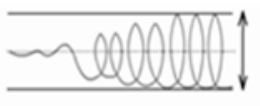

(a) Vortex Yam

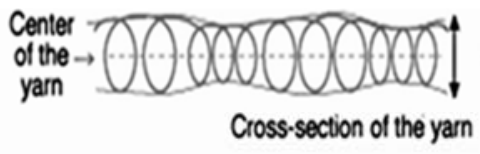

(b) Ring Yam

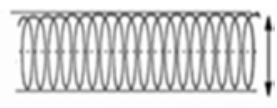

(c) Rotor Yarn

Figure 4. Cross-section of vortex, ring and rotor spun yarn [27].

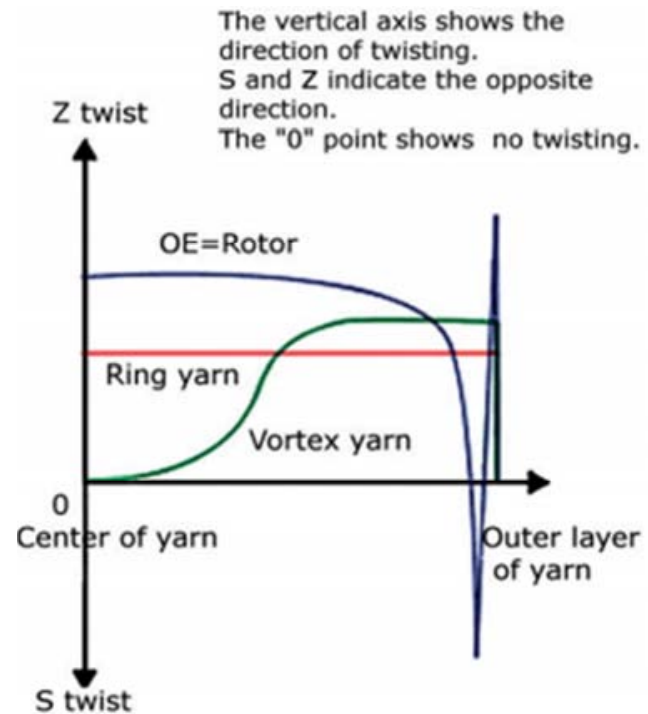

Figure 5. Difference in twist distribution in vortex, rotor and ring yarns [4].

Figure 5 compares twist in vortex, rotor and ring-spun yarn.
The figure shows that at centre of vortex yarn there is zero twist in the fibers i.e. they form a parallel alignment at the very centre. Twist increases towards the outer part of the yarn and is greatest in the outer wrapper fibres. Rotor-spun yarns have fibers twisted from the center to the outer side. For fibers near the surface of the rotor yarn, twisting is uneven. Some fibers are twisted in the opposite direction of the main bundle of rotor yarn. On the other hand, ring yarns have a relatively consistent twisted structure from the centre to the surface of the yarn body (Figure 4).

In Vortex yarn structure, the percentage of cover fibers is so high that untwisted floated core fibers are almost covered and are resemble like a real twist [18].

As fibers are not mechanically twisted in vortex spinning, the number of twists cannot be mechanically set. However, in vortex spinning, the strength of the compressed air vortex and the spinning speed are used for adjustment.

Tight regular wrappings lead to the smaller yarn diameter. Therefore yarn volume decreases, which ultimately results in lower thermal insulations. 


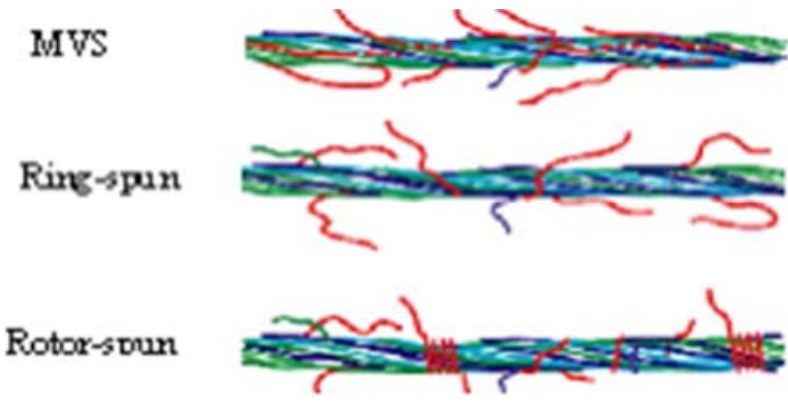

Figure 6. Ring rotor and air vortex yarns structure [19].

Ring spun yarn contains the highest proportion of normally oriented core fibers, while vortex yarn possesses the lowest proportion. In ring yarn, the core fibers are completely embedded in the yarn in a helical position, with the diameter varying as the fibers move from the inner part to the outer part and back within the yarn. No wrapper fibers appear in this yarn structure, and belly-band fibers are rare in ring yarn. The absence of twist in the core fibers of vortex yarn (Figure 6) must also be regarded as significant. Most wild fibers in vortex yam protrude from the wrapper fibers rather than the core because the core is encircled by the wrapper fibers. Fibers in a loop formation along the yarn axis are categorized as wild fibers in the vortex yarn structure. All designated fiber types are found in vortex yarn, although the occurrence of belly-band fibers is very low. The number of belly-band fibers is highest in rotor yarn [20].

\subsection{Vortex Yarn Characteristics}

The yarn becomes finer, the yarn becomes more uneven and the amount of yarn imperfections increases markedly. The regularity of the yarn mainly relies on the arrangement of the fiber within the yarn as well as the number of the fibers in the yarn cross-section. The uniform arrangement of fibers within the yarn generally deteriorates due to variations in fiber characteristics and processing. As the number of fibers in the yarn cross-section decreases, the uniform arrangements of the fibers become more difficult.

Tyagi et al. concluded that yarns with higher proportion of cotton fiber are less even and have high number of imperfections. Moreover, the yarns with higher proportion of cotton content are more hairy on account of the higher bending and torsional rigidity of cotton fiber, and flexural rigidity and abrasion resistance are considerably higher in yarns with higher polyester content [21].

Erdumlu et al reported that the tenacity of vortex spun yarns remains almost unchanged as the yarn becomes finer. They said the tenacity behavior of the vortex spun yarns can be attributed to two opposing effects: a) As the yarn becomes coarser, wrapping length of the wrapper fibers declines and this results in a decrease in tenacity and b) As the yarn becomes coarser, more will be the core fiber that will contribute to yarn tension, in other words, breaking load increases [17].

But Tyagi et al. showed that coarser yarns possess higher tenacity; they explained this behavior by the fact that as the finer yarns contain more proportion of wrapper fibers (or less proportion of load bearing fibers, namely core fibers), these yarns have lesser tenacity in comparison to the coarser ones [15].

Tenacity of air-vortex yarn is higher than tenacity of air-jet spun yarn. The higher tenacity values of vortex yarns can be attributed to the higher number of wrapper fibers in these yarns. The fiber separation from the bundle occurs everywhere in the entire outer periphery of the bundle. This results in a higher number of wrapper fibers in the yarn [13].

Vortex yarns showed statistically significant higher values of tenacity compared to the rotor yarns due to low straightening of fibers in the rotor yarn, the tenacity of individual fibres is not fully utilized in the yarn [5].

The rotor yarns show the statistically significant higher abrasion resistance compared to Vortex yarns. It is caused by the fact that the fibres are not so straightened and parallelised as core fibers in the Vortex yarn. Due to low parallelisation of fibers and thus increased number of friction points between fibres, the rotor yarn is probably able to resist the action of rotating body for a longer time while outer layer is damaged, compared to the Vortex yarn with straightened and non-twisted core fibres. The belt fibres of rotor yarn can contribute to higher abrasion resistance of rotor yarn [5].

Higher proportion of wrap fibers leads to vortex yarns lower elongations because of the wrapping fibers restricting the yarn movement. The elongation at break and breaking force values of vortex yarn are lower than that of compact spun yarn and ring yarns and higher than that of rotor yarn. The possible explanation for such mechanical properties is the relatively good fiber arrangement in the core and sheath of vortex yarn in comparison to open-end spun yarn [18].

Vortex yarns have significantly higher bending rigidity compared to rotor yarns. It is caused because Fibres are arranged more parallel in the core part of Vortex yarn whereas all fibres are formed more randomly in the rotor yarn [5]. The bending rigidity of vortex yarn is also higher than ring yarns. The reason for this is the helical coil spring structure of the ring yarn, which confers a narrower bending moment to the structure [20].

The reason for the low hairiness of vortex yarn in comparison with ring and rotor yarn is the thin layer of wrapper fibers, which prevents fibers from protruding from the main yarn body and forming wild fiber loops along the yarn axis.

\section{Properties of Fabric Made from Vortex Yarn}

The water vapor resistance and the air permeability are considered to be the most important comfort-related properties of fabrics. The presence of wrapper fibres in vortex yarn ensures less number of protruded fibers on the surface of the yarn. But in case of ring spun yarn the surface hairs cause hindrance to the air flow and hence the ring yarn fabric offers more resistance to air flow. Thus the air permeability of ring yarn fabrics is lower as compared to vortex yarn fabric [22]. 
Water vapour permeability is the ability of a fabric to transfer the perspiration in form of moisture vapour through it. A fabric with low water vapour permeability is unable to transfer sufficient moisture, leading to sweat accumulation and hence discomfort. It was observed that vortex yarn fabric had slightly higher water vapour permeability compared to ring yarn fabric. This is due to the fact that the looser structure of fibres at the centre of vortex yarns which allows water vapour to transfer from inside to outside through diffusion [22].

Vortex-spun yarns had lower yarn and fabric wicking values than ring-spun yarns. Vortex-spun yarn has a crimped yarn axis and tight wrappings along the yarn length which disturb the continuity of the capillaries [6].

Spirality, causing due to non-perpendicular disposition of wales with respect to the courses is a dimensional distortion in circular plain knitted fabrics influencing both aesthetic and functional performance of knitted fabrics during use [23]. Spirality is lower in vortex spun yarn fabrics in comparison with ring yarn fabrics. Fibers in ring yarn are arranged in different radial distance. The fibres when travel from one layer to the other due to migration, the helix angle changes. Such arrangement of fibers at different radial distance causes different degree of stress in fibers. The stress along with the imparted torsion in the fibers remains stored in fibre making the yarn twist lively. But in vortex spinning, the fibres are arranged in the structure more or less in a parallel fashion wrapped by wrapper fibres. Vortex yarns are less twist lively. Poor migration and low spinning tension internal leads to less stress development in the fibres resulting less twist lively yarn. Spirality is thus, low in vortex spun yarn fabrics [23].

On the other hand, when vortex and open-end spun yarns are compared, results imply that open-end spun yarn is less lively than vortex counterpart. This is attributed to the existence of belted fiber zones in the structure of open-end spun yarn. In addition, the arrangement of fibers in the structure of open-end spun yarn is more uneven compared to vortex yarn. Such configuration of fibers within open-end spun yarn might ease to relieve torsional energy, when compared to vortex yarn. Hence, open-end spun yarn has the lower lively yarn and moreover angle of spirality in the fabric from open-end spun yarn is lower than vortex yarn [18].

Since vortex has structurally lower hairiness, fabric printing is clearer, sharper and more attractive. Vortex is also compatible with digital printing which has recently increased in popularity [24].

Ring spun yarn is generally more irregular than vortex yarn in terms of mass and twist variation. The mass variation can also influence the twist variation. Presence of a thick place produces a soft twisted part while a thin place produces a hard twisted portion thereby giving a differential fibre integration character. A soft twisted portion of a yarn will have less holding power for its constituent fibres which will easily come out of the surface on abrading. Rubbing the fabric surface by an applied load will produce a frictional force on the fibers. If the frictional forces are greater than the cohesive forces between the fibers, then the fiber will migrate to the surface to form fuzz. In vortex yarn due to the presence of wrapper fibers the cohesive force is greater than frictional force, so there is less chance of formation of pills on fabric surface as compared to ring spun yarn [23]. Since fibres in yarns are positioned from the core to the periphery, it is difficult for them to bepulled from their position, which results in better resistance to pilling.

Shrinkage in a knitted fabric can either be due to shrinkage in yarn or due to shrinkage of the structure itself. Shrinkage due to yarn occurs when the yarn having high twist or twist liveliness in yarn is more. A twist lively yarn always shows a tendency to get relieved of the stress induced during torque application. If twist liveliness in yarn is more then there is more possibility for yarn to relax. Vortex yarn is less twist lively as compared to ring yarn so chance of shrinkage of yarn in fabric is less for vortex yarn as compared to ring yarn [23].

Higher cotton content in polyester-cotton blended vortex yarn is very effective improving absorbency and thermal insulation properties but decreases the air permeability of fabrics. Higher cotton content changes in yarn bulk and hairiness resulting in improved absorbency and thermal insulation of fabric [25].

\section{Advantages in Post Spinning Process}

The less hairiness surface of vortex yarn gives tremendous advantages in sizing process. The even and deeply penetrated sizing, because of better absorption property, results in better efficiency at loom and less consumption of sizing material also. Surface of vortex yarn also results in better loom shedding, ultimately the less breakages and the better efficiency, even with the slightly low strength.

After dyeing, the drying of fabric is required, according to quick drying property of vortex yarn, the drying of vortex fabric is quicker $\&$ the production of this machine may also be increased. On the other hand, as the vortex yarn has less spirality problem and good resistance against deformation, which make it ideal for stitching of knitted fabric. Finally, due to low pilling property of vortex yarn, it has much more laundering cycles, then that of ring spun yarn. This is ideal yarn for the fabrics which needs to have frequent $\&$ more no. of washings [26].

\section{Conclusion}

Vortex is a yarn with high function and fashion applicability, created by Vortex spinning technology. As the yarn becomes finer, proportion of wrapper fibers, the yarn unevenness and the number of yarn imperfections markedly increase. Yarns with higher proportion of cotton content are more hairy and less even. In comparison with rotor and air-jet spun yarn, the tenacity of vortex spun yarn is high whereas vortex yarn is less hairy in comparison with both ring and rotor yarn. Fabrics from vortex yarn is attributed with higher air permeability and water vapour permeability and lower wicking values and spirality compared to fabrics from ring spun yarn. 


\section{References}

[1] J. M. Bergada, E. Valencia, Li. Coll (2007), Flow Characterization in Cylinders for Pneumatic Spinning, Textile Research Journal, Volume: 77 issue: 2, page(s): 67-76

[2] Hyun Ah Kim, (2017)Physical properties of ring, compact, and air vortex yarns made of PTT/wool/modal and wearing comfort of their knitted fabrics for high emotional garments, The Journal of The Textile Institute, http://dx.doi.org/10.1080/00405000.2016.1275444

[3] Nazan Erdumlu1, Bulent Ozipek, A. Selda Oztuna and Seda Cetinkaya, Investigation of Vortex Spun Yarn Properties in Comparison with Conventional Ring and Open-end Rotor Spun Yarns, Textile Research Journal Vol 79(7): 585-595 DOI: $10.1177 / 0040517508093590$

[4] Mohamed Eldessouki, Sayed Ibrahim, Ramsis Farag, Dynamic properties of air-jet yarns compared to rotor spinning, Textile Research Journal, Volume: 85 issue: 17, page(s): 1827-1837

[5] Eva Moučková1, Iva Mertová, PROPERTIES OF VISCOSE VORTEX YARNS DEPENDING ON TECHNOLOGICAL PARAMETERS OF SPINNING, AUTEX Research Journal, Vol. 15, No 2, June 2015, DOI: 10.2478/aut-2014-0046 (C) AUTEX

[6] Nazan Erdumlu, Canan Saricam, Wicking and drying properties of conventional ring- and vortex-spun cotton yarns and fabrics, The Journal of The Textile Institute, 2013 Vol. 104, No. 12, 1284-1291, http://dx.doi.org/10.1080/00405000.2013.799258

[7] http://www.intamakina.com/Murata/VortexIII870_e.pdf

[8] https://www.rieter.com/en/machines-systems/news-center/therieter-manualofspinning/?tx_damdownloadcenter_pi $1 \% 5 \mathrm{Bfile}$ $\% 5 \mathrm{D}=176964 \& \mathrm{cHash}=90 \mathrm{e} 9 \mathrm{da} 7 \mathrm{caa}$

[9] Nazan Erdumlu, Bulent Ozipek and William Oxenham, Vortex spinning technology, Textile Progress, 44:3-4, 141-174.

[10] www.rieter.com

[11] Fiow, Zeguang Pei, Designing the Spindle Parameters of Vortex Spinning by Modeiing tiie Fiber/Air Two-Pbase Journal of Manufacturing Science and Engineering, June 2014, Vol. 136. DOI: $10.1115 / 1.4026445$.

[12] Guldemet Basal and William Oxenham, VORTEX SPUN YARN VS. AIR-JET SPUN YARN, AUTEX Research Journal, Vol. 3, No3, September 2003 (C) AUTEX

[13] N Erdumlu, W Oxenham and B Ozipek, The impact of combing and processing parameters on the structure and properties of fine count vortex yarns, Textile Research Journal 83(4) 396-405, DOI: $10.1177 / 0040517512464296$

[14] https://www.textileschool.com/455/air-jet-spinning/

[15] G K Tyagi, Influence of Processing Variables on Yarn Structural Parameters, Indian J. Fibre \& Textile Res, Vol-29, December 2004, pp 419-428

[16] Reeti Pal Singh and V K Kothari, Progress in non-conventional yarn manufacturing systems, Indian textile journal.

[17] Nazan Erdumlu, Bulent Ozipek and William Oxenham, The structure and properties of carded cotton vortex yarns, Textile Research Journal 82(7) 708-718, DOI: $10.1177 / 0040517511433150$

[18] Huseyin Gazi Ortlek and Levent Onal, Comparative Study on the Characteristics of Knitted Fabrics Made of Vortex-Spun Viscose Yarns, Fibers and Polymers 2008, Vol.9, No.2, 194-199

[19] Rameshkumar, Anandkumar et al, COMPARITIVE STUDIES ON RING ROTOR AND VORTEX YARN KNITTED FABRICS, AUTEX Research Journal, Vol. 8, No4, December 2008 C AUTEX

[20] Aung Kyaw Soe, Masaoki Takahashi \& Masaru Nakajima, Structure and Properties of MVS Yarns in Comparison with Ring Yarns and Open-End Rotor Spun Yarns, Textile Research Journal, 74(9), 819-826 (2004).

[21] Tyagi G. K., Sharma D. Performance and low-stress characteristics of polyester-cotton MVS yarns. Indian Journal of Fiber \& Textile Research. 2004; 29(September):301-307.

[22] G. Thilagavathi, N. Muthukumar, V. Kiran Kumar, Sanjay Sadasivam, Physical and Thermal Comfort Properties of Viscose Fabrics made from Vortex and Ring Spun Yarns, Journal of The Institution of Engineers (India): Series E, June 2017, Volume 98, Issue 1, pp 65-70.

[23] Dinesh Bhatia and S. K. Sinha, Comparative assessment \& empirical modeling for aesthetic behavior of vortex \& ring yarn knitted fabrics on laundering, International Journal of Fiber and Textile Research 2014; 4(4): 62-70

[24] http://www.muratec-vortex.com/feature04.html

[25] Tyagi G. K., Sharma D. Thermal comfort characteristics of polyester-cotton MVS yarns fabrics. Indian Journal of Fiber \& Textile Research. 2005; 30:363-370.

[26] http://www.ptj.com.pk/Web\%202004/08-2004/Comparison\%2 0of $\% 20$ Vortex $\% 20$ yarn.html

[27] https://nptel.ac.in 